ISSN1027-5495. Functional Materials, 24, No.4 (2017), p. 615-620

\title{
The study on permeability ratio curve of polymer/SAA binary system and two-phase of viscous crude
}

\author{
Ya-nan Wang, Ji-hong Zhang
}

\author{
Key Laboratory on Enhanced Oil and Gas Recovery of the Ministry of \\ Education, Northeast Petroleum University, Daqing, Heilongjiang, China
}

\section{Received September 8, 2017}

According to the different proportion of making up solution of the binary combination system which use of hydrophobic associating polymer and Sulfonate Gemini Surfactant, determinating of its viscosity and interfacial tension before injection. Simulation of the bohai suizhong 36-1 oilfield actual situation, the constant speed nonsteady state method is used for the determination of permeability ratio curve of water drive and binary combination drive, and the experimental data were processed by J.B.N. Method. Analysis of the pros and cons of existing several kinds of the viscosity processing methods for non-Newtonian fluid flow in the core, put forward a new method of viscosity processing, and compared the binary combination drive relative permeability curve which use of the different viscosity processing method. Laboratory findings show that the binary multisystem flooding in oil relative permeability is higher than water flooding, the water relative permeability is lower than water flooding, SOR is lower than water drive; Mass fraction of surfactant and polymer concentration of the binary multisystem have influence on the permeability ratio curve modality.

Keywords: Offshore viscous crude field; Binary combination flooding; Ultra low interfacial tension; Viscosity processing; Permeability ratio curve

Исследовано влияние бинарной комбинированной системы, в которой используется гидрофобный связывающий полимер и сульфонатное Гемини поверхностно-активное вещество на свойства раствора для заводнения пластов нефтяного промысла, его вязкость, и межфразное натяжение. Предложен новый метод анализа вязкости и проницаемости ньютоновской жидкости непосредственно в потоке просачивания. Лабораторные результаты показывают, что влияние бинарного многосистемного заводнения для относительной проницаемости масла больше, чем просто заводнение воды, относительная проницаемость воды ниже, чем затопление воды, SOR ниже, чем приток воды. Массовая доля поверхностноактивного вещества и концентрация полимера в бинарной мультисистеме оказывают влияние на коэффициент проницаемости бинарного раствора.Проведено моделирование нефтяного промысла методом нестационарного состояния с использованием J.В.N. метода.

Дослідження коефіціента проникності полімеру / SAA подвійної системи і двофазної в'язкої нафти. Ya-nan WANG, Ji-hong ZHANG

Досліджено вплив бінарної комбінованої системи, в якій використовуеться гідрофобний полімер, що зв'язуе і сульфонатна Геміні поверхнево-активна речовина на властивості розчину для заводнення пластів надртового промислу, його в'язкість, і міжсразний натяг. Запропоновано новий метод аналізу в'язкості і проникності ньютонівської рідини безпосередньо в потоці просочування. Лабораторні результати показують, що вплив бінарного багатосистемного заводнення для відносної проникності масла більше, ніж просто заводнення води, відносна проникність води нижче, ніж затоплення води, SOR нижче, ніж приплив води. Масова частка поверхнево-активної речовини і концентрація полімеру в бінарній мультисистемі впливають на коефіціент проникності бінарного розчину. Проведено моделювання нафтового промислу методом нестаціонарного стану з використанням J.B.N. методу. 


\section{Introduction}

The Bohai SuiZhong36-1 oilfield with high crude oil viscosity, high pore permeability, relatively high salinity and so on, is a typical offshore viscous crude field in our country. With the ongoing of water drive, it has gradually entered the high water cut stage, in order to expand offshore field after polymer flooding, polymer/SAA binary combination drive reservoir engineering calculation, numerical analogue and other works, we should understand binary multisystem effluent seepage law in the reservoir. Therefore, relative permeability curves of polymer/SAA binary combination drive need to be measured under the actual conditions of viscous oil reservoir.

Currently there are many abroad studies about polymer flooding permeability ratio curve, such as [1] measured the relative permeability curves of polymer flooding using the steady-state method. There are also a lot of research on chemical flood permeability ratio curve, for instance, [2] measured the oil-water relative permeability curve of low interfacial tension surfactant system. There are many literatures about determination of the polymer flooding relative permeability curve adopting astable method, for example, [3] measured the permeability ratio curve of surfactant system and polymer system, comparing with the water flooding relative permeability curve.

As non-Newtonian fluid, the polymer and binary compound solution's viscosity is changing when flow in the reservoir porous media, so how to deal with the viscosity has been the key whether the resulting curve can represent the actual seepage flow characteristics. This paper, on the basis of analysis and summary of various existing methods, proposes a new approach to deal with viscosity, and demonstrates its justifiability.

\section{Experimental}

Simulation of total salinity water used in the experiments was $9374.13 \mathrm{mg} / \mathrm{L}$, ion content of simulation of water in Table 1.

The kind of preparation binary multisystem polymer is hydrophobic associative polymer HNT300, provided by CNOOC Research Institute, a molecular weight of about $1600 \times 104$; The kind of surfactants are Sulfonate Gemini surfactant BH-M2 [4], provided by Southwest Petroleum University.

The simulation of oil, used in the experiment mix by crude oil and kerosene by a certain percentage, under $65^{\circ} \mathrm{C}$ condition viscosity $70 \mathrm{mPa} \cdot \mathrm{s}$.

The gas experimental permeability of the artificial core measured about $2500 \times 10^{-3} \mathrm{um}^{2}$. The physical properties of the core used in the experiments are similar, so it has good repeated comparative.

There are some apparatus to appraisal physical and chemical properties of binary multisystem. For example, BROOKFIELD, the digital
Table 1 The ion composition and content of the experimental simulation water

\begin{tabular}{|c|c|}
\hline Ionic composition & Ion content/mg. $\mathrm{L}^{-1}$ \\
\cline { 1 - 2 } $\mathrm{Na}^{+}$ & 3091.96 \\
\hline $\mathrm{K}^{+}$ & 276.17 \\
\hline $\mathrm{Ca}^{2+}$ & 158.68 \\
\hline $\mathrm{Mg}^{2+}$ & 5436.34 \\
\hline $\mathrm{Cl}^{-}$ & 14.21 \\
\hline $\mathrm{CO}_{3}{ }^{2-}$ & 311.48 \\
\hline $\mathrm{HCO}_{3}{ }^{-}$ & 85.29 \\
\hline $\mathrm{SO}_{2}-$ & 9374.13 \\
\hline Total salinity & \\
\hline
\end{tabular}

viscometer of DV-III, Model TX500C interfacial tensiometer. The relative permeability curve of binary multisystem is measuring by advection pump, air gauge, core holder, Pistons container and so on. Apparatus except advection pump, other instruments are placed in an incubator $65^{\circ} \mathrm{C}$.

2.1 The measurement of the viscosity and the interfacial tension before the binary multisystem injection

To the polymer/SAA multisystem, viscosity and the interfacial tension have a huge influence on the relative permeability when the twophase of the system have a relative flow. Thus we measure the viscosity and the interfacial tension of this composite system to analyze the influence of these two thing to the relative permeability curve in the test.

Viscosity measurement: use the BROOKFIELD DV-III to get the viscosity. First use the NO.0 rotor work for $30 \mathrm{~s}$ at the speed of 100rpm, after asiding for $90 \mathrm{~s}$ while perteating, we start to measure the viscosity; Experiment condition: NO.0 rotor, $6 \mathrm{r} / \mathrm{min}, \gamma=7.35 \mathrm{~s}^{-1}$, stay $65^{\circ} \mathrm{C}$.

Interfacial tension: use Model TX500C to get the viscosity of the composite system and the imitated oil(viscosity of $70 \mathrm{mPa} \cdot \mathrm{s}$ ); Experiment condition: temperature at $65^{\circ} \mathrm{C}$, speed at $6000 \mathrm{r} / \mathrm{min}$.

\subsection{The method of viscosity processing}

In this study, we use the following method to deal with the viscosity of the binary multisystem in the porous media: in the process of the experiment, the produced liquid is saved after water appears, and do the separation of oil and water. Then test the viscosity of the binary multisystem. As the water just appears, the produced oil is much more than water, the water separated is not enough to do the test, so we need to accumulate the liquid from several produced times and make it as the sample in the average PV number. Then use the different viscosity under different average PV numbers to fit a curve that viscosity changes as PV number moves. Then put the PV number needing to calculate back to the egres- 
Table 2. Experimental schemes of two element composite system

\begin{tabular}{|c|c|c|}
\hline & $\begin{array}{c}\text { Concentration of } \\
\text { polymer/mg. } \mathrm{L}^{-1}\end{array}$ & $\begin{array}{c}\text { mass fraction of } \\
\text { surfactant/\% }\end{array}$ \\
\hline 1 & 1000 & 0.05 \\
\hline 2 & 1750 & 0.05 \\
\hline 3 & 1750 & 0.2 \\
\hline 4 & 2000 & 0.2 \\
\hline
\end{tabular}

sion formula and get the viscosity at the different water saturations. Last, calculate the average number of the viscosity of the injection side and the delivery end, then you can know the average viscosity of the binary multisystem in the rock at different water saturations.

\subsection{The determination of the injection rate}

To fit the transfusion of SuiZhong 36-1 oilfield, the experiment use the speed of $3 \mathrm{~m} / \mathrm{d}(0.3 \mathrm{~m} / \mathrm{min})$. After calculation, the speed can fit the demand of the test:

$$
\mu \times L \times v \geq 1
$$

in the formation:

$\mu$ - viscosity of the displacing fluid, $\mathrm{mPa} \cdot \mathrm{s}$;

$L$ - the length of the test, cm;

$v$ - transfusion rate, $\mathrm{cm} / \mathrm{min}$.

So in this test, we use this rate of flow.

\subsection{The determination of the binary combination drive permeability ratio curve and data processing}

Binary multisystem of relative permeability experimental process and steps of determination of reference to SY/T5345-2007 rock twophase relative permeability in the latest industry standard for measuring method, the experimental data according to the basic formula of J.B.N. method [5] for sorting and calculated.

\subsection{Experimental scheme}

For contrast in the binary multisystem of polymer and surfactant on the influence of the relative permeability curve, set the following four experimental schemes, shown in Table 2.

Determination of the static viscosity and the interfacial tension of the four kinds of binary multisystem above, using the binary compound displacement system until no oil produced. Then the relative permeability curve of the four kinds of binary combination drive is obtained by computing.

\section{Results and discussion}

3.1 Comparison of several different viscosity processing method of relative permeability curve

At present, there are many methods for determination of polymer or polymer sheet bi-

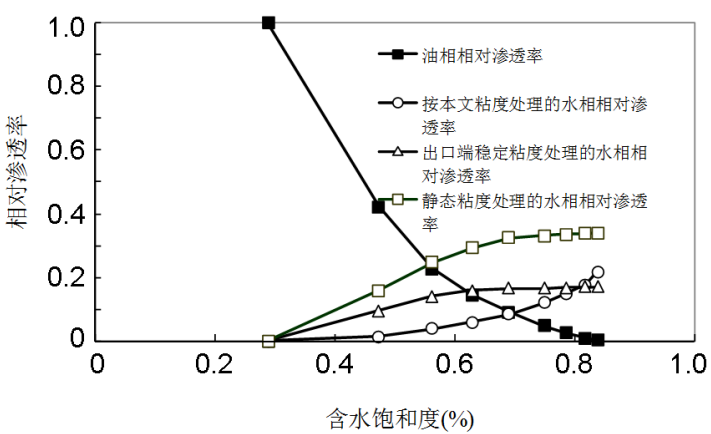

Fig. 1. Different viscosity approach can obtain binary compound flooding relative permeability curve (option 3)

nary compound system flowing in the porous medium viscosity: the first is the direct use of fluid into the porous medium before the bulk viscosity instead; Second is the outlet end displacement stable viscosity fluid; Third category is obtained from the relation the shear rate and flow of power law fluid velocity, or demanding for flow velocity and shear rate and viscosity, the viscosity of equation transformation, effectively [6-7]; The fourth kind of method is by definition the Darcy formula and the resistance coefficient and residual resistance coefficient, by the transformation to find the effective viscosity of binary composite system [8-10]. Treatment methods of relative permeability curve as shown in Figure 1.

Analysis of several methods of the above: the first kind of processing method is without considering the non-Newtonian fluid in porous media, such as the role of the residual shear viscosity, so the whole is too large, so that the water phase relative permeability is calculated systematically larger; While the second methods only take the drive outlet viscosity for close to flooding agent for the final state, ignoring the fluid with viscosity changes and changes in displacement process in rock, so that the viscosity is the real viscosity is too large, then small, also ledding to the aqueous phase calculated relative permeability changes presenting the first large then small; The theory of relationship between viscosity, shear rate and the flow velocity of the three through third methods, then transform to get the effective viscosity, rheological equation by the method without considering the displacement fluid loading on the rock; Fourth kinds of method to get the effective viscosity of fluid in rock flowing through theoretical derivation, to a certain extent, the retention of binary multisystem in porous medium and the non Newtonian effect, but still believing that the viscosity of fluid in different water saturation is the same, which cannot reflect the two element complex viscosity with 
the core saturation changes, and the experiment was carried out in oil rock, which cannot represent the actual reservoir conditions.

The first, second, fourth kinds of method are in accordance with the viscosity of a constant into relative permeability calculation formula of water, so that the relative permeability of water showed a "Hump" trend, and the actual process of binary ASP flooding are different, the seepage law of two element composite system were more accurate in in porous media. But the viscosity method used in this study considers this point, which can more realistically rendered the vary of the binary relative permeablity of oil-binary multisystem in the reservoir seepage.

\subsection{The interfacial tension and viscos- ity of binary compound system}

Table 3 shows three kinds of program about the results of measuring the interfacial tension and the viscosity of binary complex system: compared with Scheme 1,2 and Scheme 3, 4 can be found, within a certain range, the interfacial tension of binary compound system with the surfactant mass fraction increases while decreases. Moreover, when the surfactant mass fraction is $0.2 \%$ of the binary compound system can reach $10^{-3} \mathrm{mN} / \mathrm{m}$ magnitude of the ultra-low interfacial tension; Surfactants on the viscosity of binary compound system is not obvious.

\subsection{Binary combination flooding rela- tive permeability curves}

Figure 1, 2 and Figure 3 is the comparison between binary combination flooding relative permeability curves and relative permeability curves. From the overall analysis can be seen, relative permeability of flooding phase is smaller. Analyze the causes, from the computational point of view, JBN method to calculate the water phase relative permeability of the formula is:

$$
K_{r w}\left(S_{w}\right)=K_{r o}\left(S_{w}\right) \frac{\mu_{w}}{\mu_{o}} \cdot \frac{f_{w}\left(S_{w}\right)}{f_{o}\left(S_{w}\right)}
$$

Due to the large heavy oil viscosity, resulting in less water, oil viscosity, thus relative permeability of displacing phase is low. From the microscopic flooding point of view, due to the high heavy oil viscosity, flow difficulties, flooding agent flooding process requires a large force, but with heavy flooding on a larger flow resistance also cause flooding agent flow ability deteriorates. The following analysis of binary combination flooding relative permeability curves characteristics, and the binary compound system of surfactant and polymer effects on the relative permeability curves.

From the comparison of the water flooding relative permeability curves and binary combination flooding relative permeability curves in Figure 2, 3 and 4, we can discover that in the same water saturation oleic phase relative permeability of water flooding is inferior to it of binary combination flooding relative permeability, but it is opposite of the aqueous phase. The residual oil saturation of binary combination flooding is inferior to it in water flooding.

From the comparison of the water flooding relative permeability curves and binary combination flooding relative permeability curves of scheme 2 and 3 in figure 2 , we can discover that:

- In scheme 2 oil and binary composite system relative permeability is somewhat larger than them in scheme 3 , that is along with binary composite system's interfacial tension letting up, oil and binary composite system relative permeability are larger. This shows a reduction in interfacial tension, results in the oil phase and binary composite systems flow capabilities are enhanced.

- The irreducible oil saturation in scheme 3 is less than it in scheme 2, that is residual oil saturation in a certain range with decreasing interfacial tension decreases.

- Two-phase relative permeability largen analysis: when binary composite system reaching to $10^{-3} \mathrm{mN} / \mathrm{m}$ magnitude ultra-low interfacial tension, that it will drive more oil cannot flow during high interfacial tension displace-

Table 3 . The viscosity and interfacial tension of binary multisystem

\begin{tabular}{|c|c|c|c|c|c|}
\hline $\begin{array}{c}\text { polymer } \\
\text { concentration, } \\
\mathrm{mg} \cdot \mathrm{L}^{-1}\end{array}$ & $\begin{array}{c}\text { Surfactant mass } \\
\text { fraction, \% }\end{array}$ & $\begin{array}{c}\text { static state } \\
\text { viscosity, } \\
\mathrm{mPa} \cdot \mathrm{s}\end{array}$ & $\begin{array}{c}\text { interfacial } \\
\text { tension, } \\
\mathrm{mN} \cdot \mathrm{m}^{-1}\end{array}$ & $\begin{array}{c}\text { coefficient of } \\
\text { resistance }\end{array}$ & $\begin{array}{c}\text { residual } \\
\text { resistance } \\
\text { factor }\end{array}$ \\
\hline 1000 & 0.05 & 10.1 & 0.0521 & 26.2 & 9 \\
\hline 1750 & 0.05 & 26.3 & 0.0436 & 49.53 & 12.34 \\
\hline 1750 & 0.2 & 27.2 & 0.0047 & 43 & 11.06 \\
\hline 2000 & 0.2 & 33.4 & 0.0041 & 56.36 & 13.58 \\
\hline
\end{tabular}




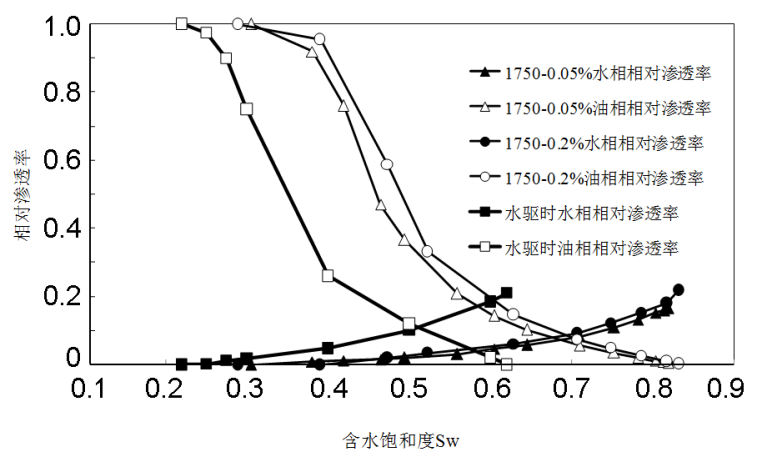

Fig. 2. Binary combination flooding relative permeability curves at different surfactants mass fraction

ment. Therefore in the same number of immitting $\mathrm{PV}$, interfacial tension reduction, increased oil production and oil production speed. Result in the oleic phase relative permeability increases. For binary composite system, on the basis of capillary pressure formula:

$$
P_{\mathrm{c}}=\frac{2 \sigma_{\mathrm{ow}} \cos \theta_{\mathrm{ow}}}{r}
$$

We can get to know capillary pressure is in direct proportion to interfacial tension. When binary composite system reaches to ultra-low interfacial tension capillary pressure is also infinitesimally small, the resistance of displacing phase trail off, it is more beneficial to flowing in porous media.

Residual oil saturation decreasing analysis: interfacial tension letting down would result in oil-water interface fade away, when it reaches to ultra-low interfacial tension, two types phase states will interdiffuse, result in miscible flowing, therefore some water film of caecum residual oil surface would be destroyed, more residual oil would flow, microscopic oil displacement efficiency enlargement, so the residual oil saturation in core will reduce.

Figure 3 is water flooding relative permeability curves and binary combination flooding relative permeability curves of scheme 1 and 2 (surfactants mass fraction both is $0.05 \%$ ), figure 4 is water flooding relative permeability curves and binary combination flooding relative permeability curves of scheme 3 and 4(surfactants mass fraction both is $0.2 \%$ ), contrasting scheme 1 and 2 , scheme 3 and 4, we can see:

In the same water saturation, binary combination flooding relative permeability of scheme 2 and 4 are respectively below scheme 1 and 3 . That is the concentration of binary composite system higher, the mobility lower, as in the figure binary combination flooding relative permeability reduces; Oleic phase relative permeability of scheme 2 and 4 are respectively high scheme 1 and 3 , but change is not obvious.
That is oleic phase relative permeability rises a little with the increasing of the concentration of binary composite system.

The residual oil saturation of scheme 2 and 4 are respectively below scheme 1 and 3 . That is for binary composite system, the residual oil saturation decreases with the increasing of polymer concentrations.

Two-phase relative permeability changing analysis: polymer molecules in solution produce adsorption, mechanical trapping and hydrodynamic trapping effect in the minds of the rock pores, roared the wall, and then stranded in the core, resulting in the flow channel binary composite system narrow down, reduces the fluid ability of binary composite system in the core; At the same time, polymer molecule generate stronger role hydrogen bond with water molecules, resulting in the absorption of adsorbed layer to water molecules strengthen and binary combination flooding relative permeability significant reductions. Polymer concentration in the binary composite system higher, these two functions more intense, reduction of binary combination flooding relative permeability larger polymer molecule cannot have much of an effect on oleic phase flowing, and forming adsorption layer in the rock wall of the hole, resulting in the pore wall more smooth, the flow resistance of oil phase flowing in the core lower to a certain degree, thus resulting in relative permeability of oil phase become larger.

Analysis for residual oil saturation decreases: polymer molecule mutually could effectively improve the fluidity of binary composite system, resulting in the microscopic sweep efficiency increased; On the other hand, because of polymer viscoelasticity, its stretch elastic deformation would fill out the partial pressure in the core, resulting in more residual oil flowing. As a result, the enlargement of polymer concentrations would render residual oil saturation lower.

\section{Conclusions}

Binary compound flooding prepared by use of hydrophobic associating polymer with sulfonate Gemini surfactant in surfactant mass fraction of $0.1 \%-0.2 \%$, interfacial tension can reach the magnitude of $10^{-3} \mathrm{mN} / \mathrm{m}$.

Analysis of the several current processing advantages and disadvantages of non-Newtonian fluid flow in porous medium viscosity, found that viscosity method introduced in this paper is more accurate and reasonable.

The oil phase relative permeability of binary combination drive is higher than water flooding, the water phase relative permeability is lower than water flooding. Residual oil saturation of binary compound drive is lower than water flooding. 


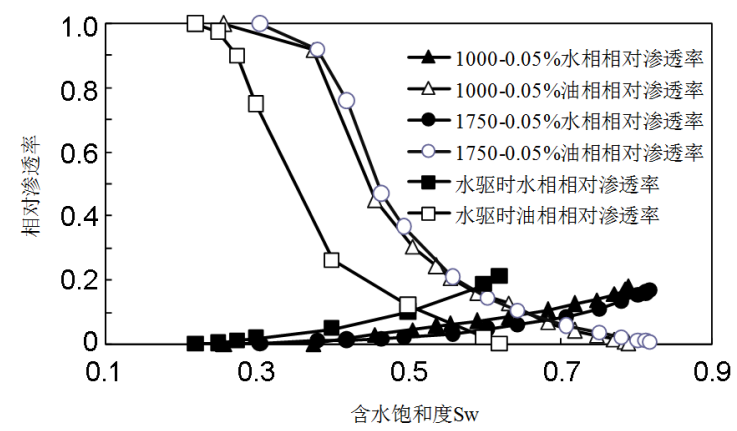

Fig. 3. Binary combination flooding relative permeability curves at different polymer concentrations (Mass fraction of surfactant is $0.05 \%$ )

With the increase mass fraction of surface active agent in the system of binary compound flooding, both the additional composite and oil phase are relatively increased while the residual oil saturation decreased. With the increase of polymer concentration in the composite system, relative permeability will decrease and residual oil saturation will be reduced.

\section{Acknowledgements}

Project supported by the National Natural Science Foundation of China (No: 51274070).

\section{References}

1. F.N. Schneider, W. Owens, Steady-State Measurements of Relative Permeability for PolymerOil Systems[R]. SPE 9408, 1980.

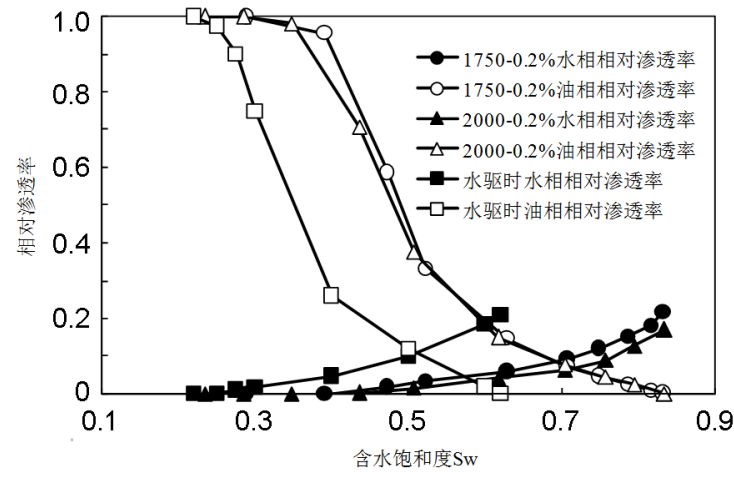

Fig. 4. Binary combination flooding relative permeability curves at different polymer concentrations (Mass fraction of surfactant is $0.2 \%$ )

2. Lu Guangqin, Wang Yudou, Chen Yueming, et al.,J. Oilfield Chem, 20, 54, 2003.

3. Wei Min, Lee Ben, Lee Hui, etc. J.Special Rreservoirs, 3, 101, 2010.

4. Zhang Xinming, Guo Yongjun, Feng Rusen, etc, J.Oilfield Chem., 29, 322,2012.

5. Johnson E. et al., Trans. AIME , 216,370, 1959.

6. Lei Guanglun. J.Petroleum University (natural science edition), 19, 1994.

7. Wang Weiying, J.Jianghan Petroleum Institute, 2, 65, 1995.

8. Shi jingping, Lee Fengqin, Cao Weizheng, etc. J. Daqing Petrol. Geol.Develop, 10,53, 2010.

9. Liu Li, Song Kaoping, Pi Yanfu, etc., J.Oilfield Chem., 28, 45, 2011.

10. Tang Jinxing, Chen Tielong, He Jinsong, et al, J. Oil, 19, 81, 1997. 